\title{
Contemporary Management of Complex and Non-Complex Rhegmatogenous Retinal Detachment Due to Giant Retinal Tears
}

This article was published in the following Dove Press journal: Clinical Ophthalmology

\author{
Katie $\times \mathrm{Li}^{1}$ \\ Nicholas Carducci' \\ Omar Moinuddin (ID) \\ Yunshu Zhou (D) \\ David C Musch ${ }^{1,2}$ \\ David N Zacks' \\ Cagri G Besirli' \\ Thomas J Wubben (1D) \\ 'Department of Ophthalmology and \\ Visual Sciences, University of Michigan, \\ Ann Arbor, MI, USA; ${ }^{2}$ Department of \\ Epidemiology, University of Michigan, \\ Ann Arbor, MI, USA
}

Purpose: To investigate the clinical features and surgical outcomes of rhegmatogenous retinal detachment (RRD) associated with giant retinal tears (GRTs) at a tertiary referral center.

Patients and Methods: A retrospective, non-consecutive interventional case series of GRT-associated RRDs that underwent primary surgical repair at the University of Michigan W.K. Kellogg Eye Center between January 1, 2011 and July 1, 2020. Clinical characteristics and preoperative, perioperative, and postoperative data were collected.

Results: Forty-eight eyes of 47 patients with GRT-associated RRDs met inclusion criteria, including those that were children (under 12 years, $\mathrm{N}=4,8.3 \%$ ), associated with a history of trauma $(\mathrm{N}=20,41.7 \%)$ or with grade $\mathrm{C}$ proliferative vitreoretinopathy (PVR-C) $(\mathrm{N}=7$, $14.6 \%$ ) at baseline. Median age was 46 years (interquartile range (IQR): 29 years, range: 4 to 72 years), median follow-up was 28 months (IQR: 43 months, range: 3-124 months), and $83.3 \%(\mathrm{~N}=40)$ of subjects were male. Primary surgical repair for GRT-associated RRDs included pars plana vitrectomy (PPV) $(\mathrm{N}=40,83.3 \%$ ), scleral buckle (SB) $(\mathrm{N}=1,2.1 \%)$, or combined PPV/SB (N=7, 14.6\%). Surgical approach commonly involved the use of perfluorocarbon liquid $(\mathrm{N}=43,90 \%)$ and gas tamponade $(\mathrm{N}=39,81 \%)$. Single surgery anatomic success (SSAS) was 75\% (95\% CI: 60\%, 85\%) at 3 months and $65 \%(95 \mathrm{CI}: 47 \%, 78 \%)$ at 2 years. Final anatomic success was achieved in all 48 eyes (100\%). Median visual acuity improved from 20/250 preoperatively to $20 / 60$ at final follow-up, with $44 \%$ ( $N=20)$ of eyes achieving postoperative visual acuity of $20 / 40$ or better.

Conclusion: In this series from a tertiary referral center, both complex and non-complex GRT-associated RRDs were most commonly managed with PPV alone, perfluorocarbon liquid, and gas tamponade with favorable final anatomic and visual outcomes comparable to other modern GRT series.

Keywords: giant retinal tear, proliferative vitreoretinopathy, retinal detachment, scleral buckle, trauma, vitrectomy

\section{Introduction}

A giant retinal tear (GRT) is defined as a full-thickness retinal tear of at least three clock hours $\left(90^{\circ}\right)$ in the circumferential span. ${ }^{1}$ GRTs are reported at an incidence of approximately 0.091 per 100,000 individuals and are present in up to $1.5 \%$ of rhegmatogenous retinal detachments (RRDs)., ${ }^{2,3}$ GRTs usually occur spontaneously but can be associated with risk factors including young age, trauma, high myopia, and hereditary conditions, such as Marfan syndrome and Stickler syndrome. ${ }^{4-6}$
Correspondence: Thomas J Wubben Department of Ophthalmology and Visual Sciences, University of Michigan Medical School, 1000 Wall St, Ann Arbor, MI, 48105, USA

Tel + I 7349368072

Email twubben@med.umich.edu 
The surgical treatment options for GRT are similar to those for primary non-complex RRD and include scleral buckle (SB), pars plana vitrectomy (PPV), and PPV with SB. ${ }^{6,7}$ Despite the advents of improved intraoperative viewing systems, small gauge surgical instrumentation, and tamponade agents, the management of GRTassociated RRDs still poses significant challenges. In addition to the many complications and technical difficulties involved, repairs of GRT-associated RRDs result in relatively high rates of surgical failure compared to those for primary non-complex RRDs, which may lead to multiple re-operations and less favorable visual outcomes. ${ }^{6,8-14}$

In the contemporary era of small-gauge vitreoretinal surgery, there are multiple case series examining the outcomes of GRT-associated RRDs (Table 1). Despite these aggregate data, there is still no consensus on management due to the small, retrospective nature of such studies. Given the relative rarity of GRTs, conducting large prospective or randomized controlled clinical studies is not clinically feasible. Additionally, published series are difficult to compare due to differences in clinical presentations, surgical techniques, and eligibility criteria. With many studies not including complex etiologies of GRTs found in pediatric patients, penetrating ocular trauma, proliferative vitreoretinopathy (PVR), or syndromic RRDs, there is an unmet need for an assessment of all-encompassing GRT-associated RRDs. The aim of the study is to investigate the functional and anatomic outcomes of surgical repair for all-inclusive retinal detachments due to GRTs.

\section{Patients and Methods}

This study was approved by the Institutional Review Board of the University of Michigan (Ann Arbor, MI, USA) and is in accordance with the guidelines by the Declaration of Helsinki. The research was conducted in compliance with the Health Insurance Portability and Accountability Act (HIPAA) and all patient data were deidentified upon review.

This is a retrospective, non-consecutive, interventional case series of patients undergoing primary repair for GRTassociated RRDs at the University of Michigan W.K. Kellogg Eye Center between January 1, 2011 and July 1, 2020.

\section{Data Collection}

All cases of non-complex and complex RRDs were identified using a combination of Current Procedural Terminology (CPT) billing and tracking codes, International Classification of
Diseases 9 th and $10^{\text {th }}$ Revision codes, and procedure codes internal to the University of Michigan (Supplemental Table 1). Medical records were then reviewed to verify coding information and to assess documentation of GRT. Subjects were included if documented to have a full-thickness retinal tear of at least three clock hours in the circumferential span on the preoperative examination or intraoperatively. Preoperative, perioperative, and postoperative information were collected from the text, drawings, photography, and diagrams found in office visit encounters, operating reports, and referral communication notes stored within the electronic medical record (Epic Systems Corporation, Verona, WI, USA).

The study population included patients diagnosed with GRT-associated RRDs that underwent primary surgical repair with $\mathrm{PPV}, \mathrm{SB}$, or $\mathrm{PPV} / \mathrm{SB}$ at the University of Michigan W.K. Kellogg Eye Center between January 1, 2011 and July 1, 2020. The aggregated data included children, subjects with a history of trauma including openglobe injury, hereditary vitreoretinopathies, or those with grade $\mathrm{C}$ proliferative vitreoretinopathy (PVR-C) at baseline. This study excluded subjects with fewer than 90 days of documented postoperative follow-up.

A total of 1999 cases of RRDs were initially reviewed during this time period. Of the eyes reviewed, 69 cases of GRT-associated RRD were identified and 21 cases were excluded due to the aforementioned exclusion criteria, resulting in 48 eyes of 47 patients that were included in the final dataset.

History of ocular trauma was defined as trauma within 6 months prior to the onset of surgery. Retinal breaks were classified as inferior if they were below the horizontal meridian bisecting 3:00 and 9:00 clock hours. Nonphakic eyes were defined as those with aphakia or pseudophakia at the time of initial GRT repair.

\section{Outcome Measures}

Data were collected postoperatively at 1 day, 1 week, 1 month, 3 months, and most recent follow-up date. Anatomic success was measured by single surgery anatomic success (SSAS) or occurrence of a single operation retinal reattachment, and final anatomic success (FAS) or occurrence of final retinal reattachment regardless of the number of surgeries. Kaplan-Meier analysis was used to estimate the long-term probability of sustained reattachment and compare group success rates between phakic and non-phakic eyes with the Log rank test.

Functional success was represented by a change in visual acuity (VA) from baseline to the most recent 


\begin{tabular}{|c|c|c|c|c|c|c|c|c|}
\hline 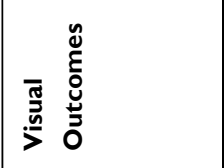 & 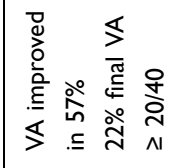 & 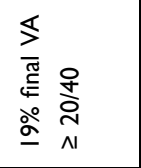 & 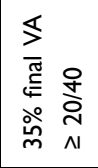 & 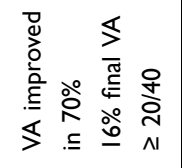 & 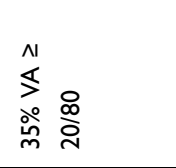 & 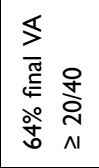 & 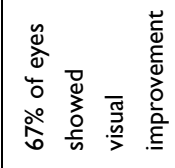 & 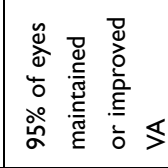 \\
\hline 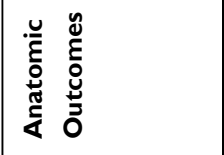 & 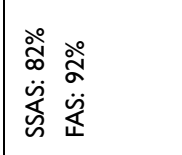 & 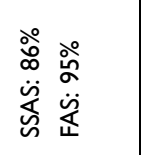 & 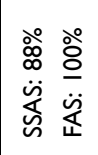 & 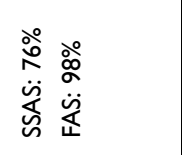 & $\begin{array}{l}\stackrel{0}{\infty} \\
\infty \\
\ddot{0} \\
\stackrel{4}{4}\end{array}$ & 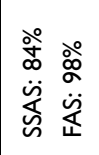 & 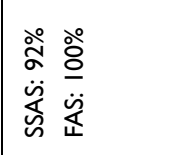 & 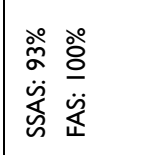 \\
\hline ○ & ڤ̊ํ & ஓ̊ & \begin{tabular}{|c}
$\stackrel{\circ}{\infty}$ \\
\end{tabular} & 。ㅇ & $\stackrel{\circ}{\aleph}$ & 。̊ & 。̊ & 商 \\
\hline 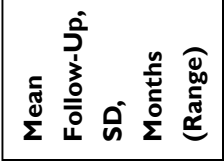 & 商 & $\begin{array}{l}a \\
+1 \\
0 \\
\end{array}$ & $\begin{array}{l}\widehat{\tilde{y}} \\
\tilde{m} \\
\underline{1}\end{array}$ & 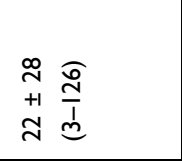 & $\begin{array}{l}\frac{0}{1} \\
1 \\
0 \\
0\end{array}$ & $\begin{array}{l}m \\
m \\
+1 \\
m \\
m\end{array}$ & $\begin{array}{ll}0 & \\
++ & \widehat{o} \\
\simeq & b \\
\hat{b}\end{array}$ & $\begin{array}{ll}\infty & \widehat{\sigma} \\
+1 & \underline{i} \\
\pm & b\end{array}$ \\
\hline 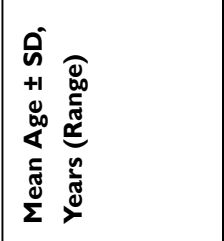 & $\begin{array}{l}\frac{\infty}{+1} \\
+\end{array}$ & $\begin{array}{l}\stackrel{0}{+1} \\
\stackrel{+1}{\infty}\end{array}$ & 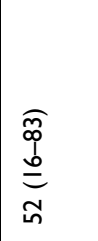 & 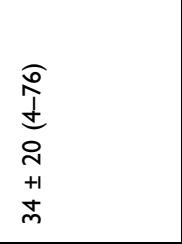 & 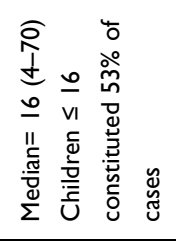 & $\begin{array}{l}\widehat{\sigma} \\
0 \\
0 \\
\underline{m} \\
\underline{m} \\
+1 \\
\tilde{y} \\
\end{array}$ & $\begin{array}{l}n \\
n+1 \\
q \\
q\end{array}$ & 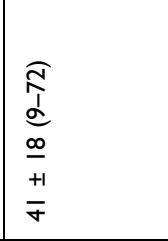 \\
\hline 岕 & হ & ০ & 丳 & ธิ & $\simeq$ & ๖ & $\simeq$ & $\bar{\sigma}$ \\
\hline 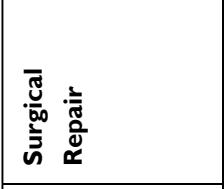 & 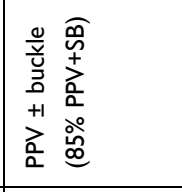 & 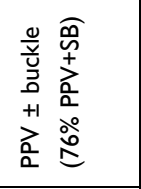 & 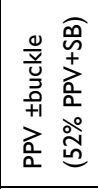 & 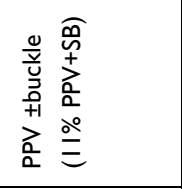 & $\begin{array}{l}\frac{0}{0} \\
\frac{0}{\pi} \\
\frac{a}{a} \\
\end{array}$ & 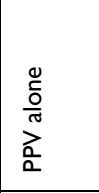 & 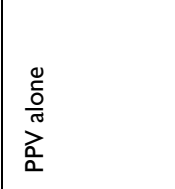 & 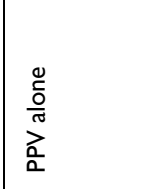 \\
\hline 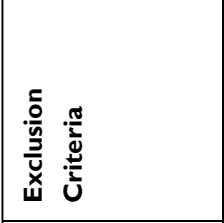 & 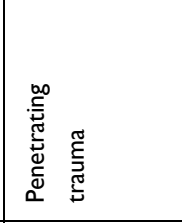 & 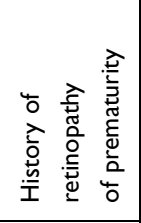 & 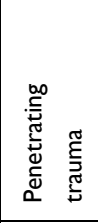 & 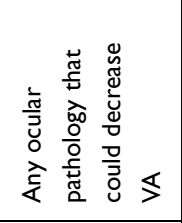 & 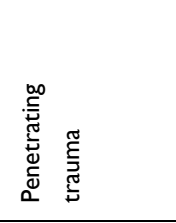 & 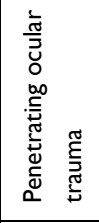 & 节 & 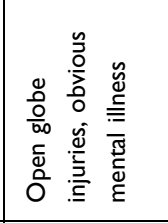 \\
\hline 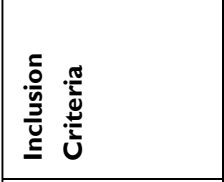 & 樖 & 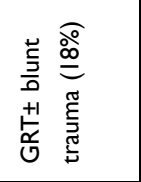 & 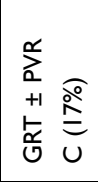 & 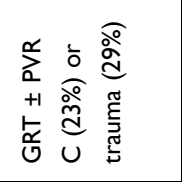 & 点 & 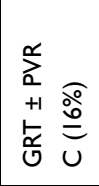 & 寽 & 樖 \\
\hline 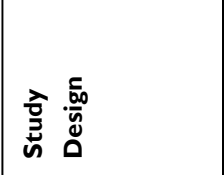 & 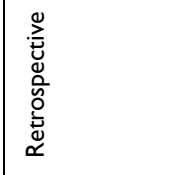 & 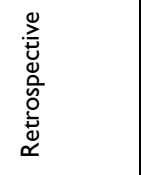 & 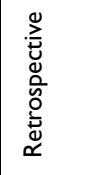 & 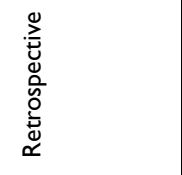 & 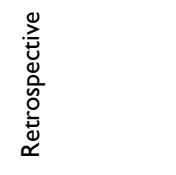 & 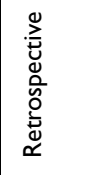 & 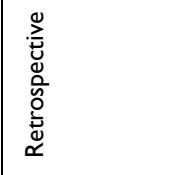 & 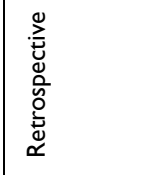 \\
\hline 童 & 范喜 & 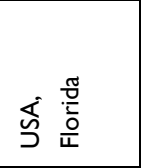 & 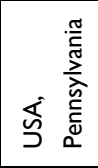 & 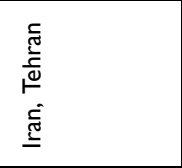 & 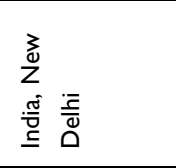 & 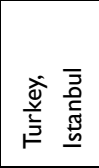 & 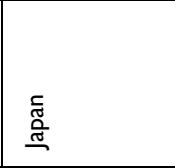 & $\begin{array}{l}\text { 总 } \\
\text { 胥 } \\
\end{array}$ \\
\hline 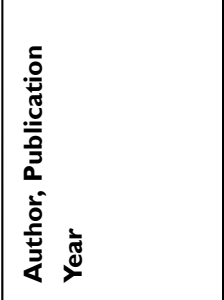 & 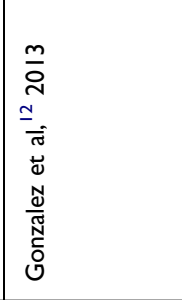 & 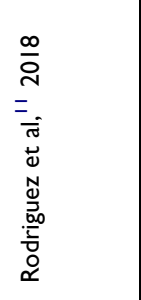 & 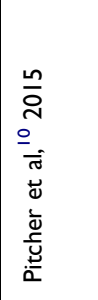 & 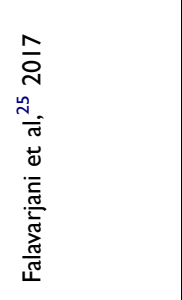 & 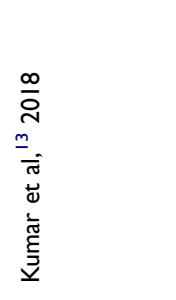 & 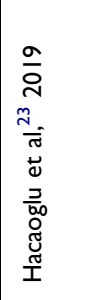 & 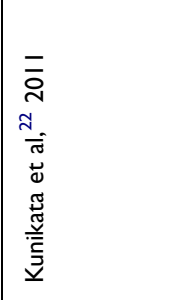 & 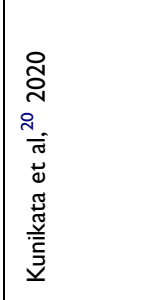 \\
\hline
\end{tabular}




\begin{tabular}{|c|c|c|}
\hline 离 & 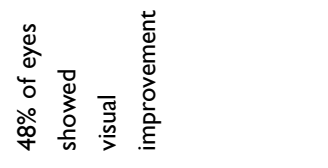 & 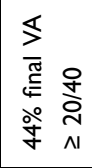 \\
\hline 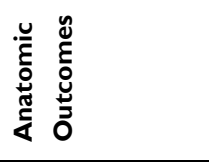 & 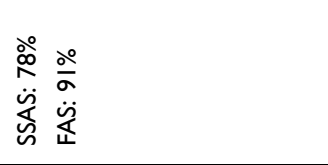 & 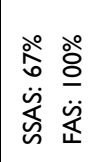 \\
\hline ㅇ & 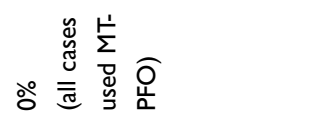 & $\stackrel{\circ}{\circ}$ \\
\hline 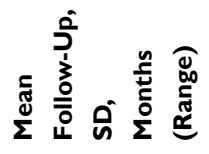 & $\begin{array}{l}\stackrel{i}{1} \\
+1 \\
m\end{array}$ & 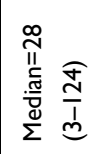 \\
\hline 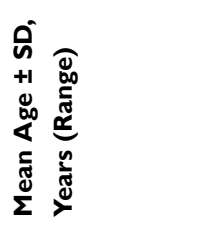 & $\begin{array}{l}= \\
+1 \\
0 \\
\text { in }\end{array}$ & 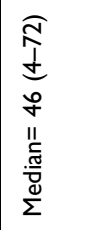 \\
\hline$\underset{\text { d }}{\tilde{u}}$ & $\tilde{\sim}$ & 号 \\
\hline 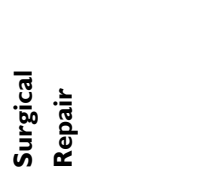 & $\begin{array}{l}\frac{0}{0} \\
\frac{0}{\pi} \\
\frac{2}{a}\end{array}$ & 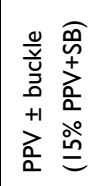 \\
\hline 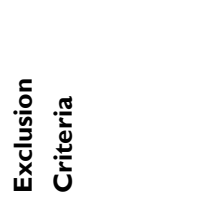 & 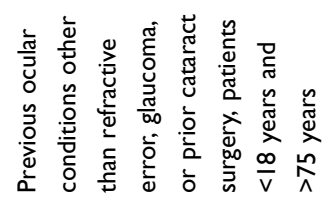 & $\stackrel{\circ}{\circ}$ \\
\hline 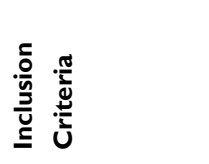 & 㰻 & 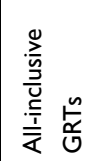 \\
\hline 希喆 & 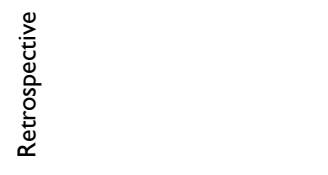 & 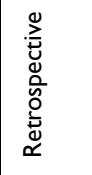 \\
\hline 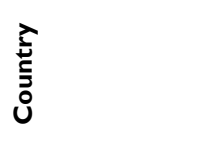 & 它 & 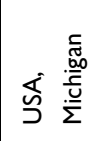 \\
\hline 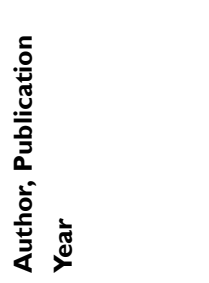 & 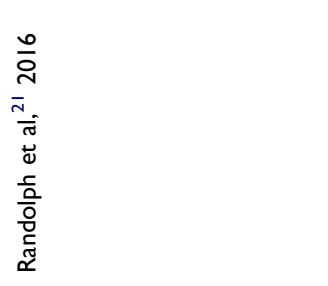 & 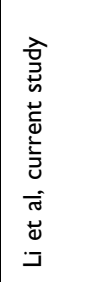 \\
\hline
\end{tabular}

follow-up. Pinhole Snellen visual acuity was used in place of best-corrected visual acuity due to reliance on available data in the medical records. For outcome calculations, Snellen VA was converted to the logarithm of the minimum angle of resolution (logMAR) equivalent. Subjects with count fingers (CF), hand motion (HM), light perception (LP), or no light perception (NLP) visual acuity were assigned values of 2.6, 2.7, 2.8, and 2.9, respectively. ${ }^{15}$ Additionally, two patients were cognitively unable to perform visual acuity testing, so they were not included in this outcome measure.

Surgical technique and variables were at the discretion of the attending surgeon and were analyzed for their effect on rates of anatomic success (chi-square test) and visual acuity at the last documented visit (Fisher exact test). Means were compared using the Student's $t$-test. Statistical significance was defined at $p<0.05$. All statistical analyses were performed using SPSS version 27.0 (IBM Corporation, Armonk, NY, USA).

\section{Results}

This study identified 48 eyes of 47 patients with GRTassociated RRD that underwent primary repair with either $\mathrm{PPV}, \mathrm{PPV} / \mathrm{SB}$, or SB alone. The majority of patients were male $(\mathrm{N}=40,83 \%)$, with a median age of 46 years (interquartile range (IQR): 29 years, range $4-72$ years) and a median follow-up of 28 months (IQR: 43 months, range: $3-124$ months). Four patients (9\%) were under the age of 12,24 patients $(51 \%)$ were between 12 and 50 years old, and 19 patients (40\%) were over the age of 50. Right eyes were involved in $50 \%$ of cases $(\mathrm{N}=24$, Table 2$)$. Risk factors for the development of GRT were history of trauma $(\mathrm{N}=20,42 \%)$, high myopia ( $-6 \mathrm{D}$ or higher, $\mathrm{N}=3,6 \%)$, Marfan syndrome $(\mathrm{N}=1,2 \%)$, and inherited vitreoretinopathies such as Stickler syndrome ( $\mathrm{N}=1,2 \%)$. Additionally, seven cases (15\%) had a history of a prior $\mathrm{RD}$ in the other eye.

The majority $(\mathrm{N}=31,65 \%)$ of eyes were phakic at presentation of which seven underwent pars plana lensectomy $(\mathrm{N}=4)$ or Kelman phacoemulsification (KPE) and intraocular lens (IOL) implantation $(\mathrm{N}=3)$ at the time of primary GRT repair. The extent of the GRT was $<180^{\circ}$ in 35 eyes (73\%) and located inferiorly in 29 eyes $(60 \%)$. At presentation, the majority ( $\mathrm{N}=31,65 \%)$ of GRT-associated RRDs were macula-off and 7 eyes (15\%) presented with grade C PVR. ${ }^{16}$ Median preoperative $\operatorname{logMAR}$ visual acuity was 1.1 (Snellen equivalent 20/252, IQR: 2.3), ranging from 0 to 2.8 (Table 2). 
Table 2 Initial Demographic, Anatomic, and Functional Characteristics

\begin{tabular}{|c|c|}
\hline & $\mathbf{N}=48(\%)$ \\
\hline Median age, years (IQR, range) & $46(29,4-72)$ \\
\hline \multicolumn{2}{|l|}{ Sex } \\
\hline Male & $40(83.3)$ \\
\hline Female & $8(16.7)$ \\
\hline Median follow-up time, months (IQR, range) & $28(43,3-124)$ \\
\hline \multicolumn{2}{|l|}{ Eye } \\
\hline Right & $24(50)$ \\
\hline \multicolumn{2}{|l|}{ Extent of GRT } \\
\hline$<180^{\circ}$ & 35 (72.9) \\
\hline$\geq 180^{\circ}$ & $13(27.1)$ \\
\hline \multicolumn{2}{|l|}{ Location of GRT } \\
\hline Inferior & $29(60.4)$ \\
\hline Superior & $19(39.6)$ \\
\hline \multicolumn{2}{|l|}{ Macula status } \\
\hline On & $17(35.4)$ \\
\hline Off & $31(64.6)$ \\
\hline Grade C PVR & $7(14.6)$ \\
\hline \multicolumn{2}{|l|}{ Lens status } \\
\hline Phakic & $31(64.6)$ \\
\hline Non-phakic & $17(35.4)$ \\
\hline Median baseline logMAR VA (IQR, range) & I.I $(2.3,0-2.8)$ \\
\hline
\end{tabular}

Note: Non-phakic includes eyes with aphakia or pseudophakia at the time of initial surgery.

Abbreviations: GRT, giant retinal tear; PVR, proliferative vitreoretinopathy; logMAR, logarithm of the minimum angle of resolution; VA, visual acuity; IQR, interquartile range.

In this study, PPV alone was the most common surgical technique utilized in the management of GRT-associated RRDs $(\mathrm{N}=40,83 \%)$. Seven eyes $(15 \%)$ underwent combined PPV/SB and one eye (2\%) had a primary SB. Notably, only one eye with a superior GRT received an $\mathrm{SB}$, while seven eyes with inferior GRTs received SBs. All PPVs were performed with either 23-gauge (38\%) or 25gauge $(62 \%)$ instrumentation. The surgical approach commonly involved the use of perfluorocarbon liquid $(\mathrm{N}=43$, 90\%). Regarding internal tamponade, perfluoropropane $\left(\mathrm{C}_{3} \mathrm{~F}_{8}\right)$ was used in most cases $(\mathrm{N}=39,81 \%)$ with silicone oil instilled following a fluid-air exchange in only 9 eyes (19\%, Table 3).

The retina was reattached at the most recent follow-up in all 48 eyes (FAS $=100 \%$, Table 4). The Kaplan-Meier estimate of SSAS was $75 \%$ ( $95 \%$ confidence interval (CI): $60 \%, 85 \%)$ at 3 and 6 months, $72 \%$ at 1 year (95\% CI:
Table 3 Operative Approach

\begin{tabular}{|l|l|}
\hline Operative Parameters & N (\%) \\
\hline Primary SB & $\mathrm{I}(2.1)$ \\
\hline Primary PPV & $40(83.3)$ \\
\hline Combined PPV/SB & $7(14.6)$ \\
\hline $\begin{array}{l}\text { Lensectomy or cataract surgery at time of primary } \\
\text { procedure }\end{array}$ & $7(14.6)$ \\
\hline Perfluorocarbon liquid use & $43(89.6)$ \\
\hline $\begin{array}{l}\text { Tamponade } \\
\text { C }_{3} \mathrm{~F}_{8}\end{array}$ & $39(81.3)$ \\
Silicone oil & $9(18.7)$ \\
\hline
\end{tabular}

Abbreviations: SB, scleral buckle; PPV, pars plana vitrectomy; $\mathrm{C}_{3} \mathrm{~F}_{8}$, perfluoropropane.

$56 \%, 83 \%)$, and $65 \%$ at 2 years ( $95 \%$ CI: $47 \%, 78 \%)$. The estimate of the proportion of non-phakic eyes that had primary successful reattachment at 3 months and 2 years was $82 \%$ (95\% CI: 55\%, 94\%) (Supplemental Figure 1). The estimate of the proportion of phakic eyes that had primary surgical success was $71 \%$ (95\% CI: $52 \%, 84 \%$ ) at 3 months and $56 \%(95 \% \mathrm{CI}: 35 \%, 73 \%)$ at 2 years (Supplemental Figure 1). This difference did not meet statistical significance $(P=0.1489)$. Recurrent retinal detachment occurred at a median of 1.63 months (IQR: 5.53 months) following the first operative intervention, ranging from 0.23 to 37.20 months after primary repair, and was attributed to postoperative PVR formation in $63 \%$ of these redetachment cases $(\mathrm{N}=10 / 16)$. Interestingly, four of the redetachments occurred at greater than 6 months post initial repair, with one redetachment occurring over 3 years out from the initial repair. All cases of recurrent retinal detachment underwent additional surgery, with $12 / 16$ eyes $(75 \%)$ requiring a total of two surgeries and 4 eyes (25\%) undergoing three surgeries (Table 4). Among the 16 cases that failed primary surgery, $12(75 \%)$ eyes initially received gas and $4(25 \%)$ eyes initially received silicone oil; during the subsequent surgeries, 7 (44\%) eyes received gas and 9 (56\%) eyes received oil.

Median postoperative $\log$ MAR visual acuity was 0.48 (Snellen 20/60, IQR: 0.64), ranging from 0 to 2.9. Final logMAR BCVA was 0.30 (Snellen 20/40) or better in 20 of 46 eyes (44\%) and worse than 1.00 (Snellen 20/200) in 9 eyes $(20 \%$, Table 5$)$.

Of all the baseline characteristics and surgical factors, only macular attachment status prior to surgery $(P=0.026)$ 
Table 4 Anatomic Outcomes

\begin{tabular}{|l|l|}
\hline Outcome & Estimate \\
\hline Final anatomic success, N (\%) & $48(100 \%)$ \\
\hline Estimated single surgery anatomic success (\%, & \\
$95 \% \mathrm{Cl})$ at: & $75 \%(60 \%, 85 \%)$ \\
3 months $^{\mathrm{a}}$ & $75 \%(60 \%, 85 \%)$ \\
6 months $^{\mathrm{a}}$ & $72 \%(56 \%, 83 \%)$ \\
I year & \\
2 years $^{\mathrm{a}}$ & $65 \%(47 \%, 78 \%)$ \\
\hline Recurrent detachment, N (\%) & $16(33.3 \%)$ \\
Presence of PVR & $10 / 16(62.5 \%)$ \\
Subsequent SB & $4 / 16(25 \%)$ \\
Median redetachment time after primary & $1.633(5.53$, \\
repair, months (IQR, range) & $0.23-37.20)$ \\
\hline Total number of repairs, N (\%) & \\
I & $32(66.7 \%)$ \\
2 & $12(25 \%)$ \\
3 & $4(8.3 \%)$ \\
\hline
\end{tabular}

Note: ${ }^{a}$ Kaplan-Meier estimate and $95 \%$ confidence intervals (\%).

Abbreviations: $\mathrm{Cl}$, confidence interval; PVR, proliferative vitreoretinopathy; SB, scleral buckle; IQR; interquartile range.

was associated with an improved likelihood of primary surgical success (Table 6). Single surgery success was achieved in 15/17 (88\%) eyes with macula-on detachments compared to $17 / 31$ (55\%) in eyes with macula-off detachments. Furthermore, macula-off detachments trended toward having larger GRTs $\left(84.6 \%\right.$ vs $15.4 \% 180^{\circ}$ or greater, $P=0.099$ ) and were more likely to be inferior (82.8\% vs $17.2 \%, P<0.01)$. Overall, the subgroup that received an $\mathrm{SB}$ had a higher $\operatorname{SSAS}(86 \%, \mathrm{~N}=7 / 8)$ than those that did not $(65 \%, N=26 / 40)$, although this did not meet statistical significance $(P=0.17)$. Out of the eight SBs placed, seven were placed in phakic eyes $(87.5 \%)$. When comparing GRT size, SSAS rates for those with a GRT < $180^{\circ}(\mathrm{N}=26 / 35,74 \%)$ trended higher than those with a $\operatorname{GRT} \geq 180^{\circ}(\mathrm{N}=6 / 13,46 \%, P=0.09)$. Additionally, superior GRTs had an SSAS of 79\% $(\mathrm{N}=15 / 19)$ and inferior GRTs had an SSAS of $59 \%(\mathrm{~N}=14 / 17, P=0.213) . \mathrm{C}_{3} \mathrm{~F}_{8}$ and silicone oil tamponade agents had similar SSAS rates (69\% vs $55 \%, P=0.457)$. The SSAS of pediatric $(<12$ years) GRTs was $50 \%(\mathrm{~N}=2 / 4)$ while the SSAS of adult GRTs was $68 \%(\mathrm{~N}=30 / 44)$. Interestingly, patients with a history of ocular trauma had comparable SSAS rates to those without $(75 \% \quad(\mathrm{~N}=15 / 20) \quad$ vs $61 \% \quad(\mathrm{~N}=17 / 28)$, $P=0.36)$. The presence of other GRT risk factors, including high myopia ( $\geq-6 \mathrm{D})$, Stickler syndrome, and Marfan syndrome, did not predispose subjects to further surgery for recurrent RDs $(50 \%$ SSAS vs $70 \%$ SSAS, $P=0.41)$. However, the number of subjects with such predisposing risk factors was small.

\section{Discussion}

In the past two decades, the introduction of perfluorocarbon liquid, wide-angle viewing systems, and microincision vitrectomy surgery has improved attachment rates of GRTassociated RRDs from about $20-40 \%$ to over $80 \%$ (Table 1). ${ }^{10-12,17-20}$ The current study shows that PPV with PFO and gas tamponade is the most frequently performed operation in the management of such cases at our institution. The results show that this surgical method provides relatively high primary success rates and $100 \%$ final retinal reattachment, which relates to the favorable visual outcomes, despite the all-encompassing nature of GRTs that were included, such as the complex management of children and eyes with syndromic abnormalities, trauma, and frequently encountered PVR at baseline.

Success during primary GRT repair is crucial, as the sizable GRT exposes a large area of retinal pigment epithelium that can easily progress to PVR if reattachment fails. $^{20}$ Prior to the era of small gauge surgery, the

Table 5 Functional Outcomes

\begin{tabular}{|c|c|c|c|c|c|c|}
\hline \multirow[t]{2}{*}{ Visual Acuity Range } & \multicolumn{2}{|c|}{ All Eyes, $\mathrm{N}=46,(\%)$} & \multicolumn{2}{|c|}{ Macula-On Eyes, $\mathbf{N}=17,(\%)$} & \multicolumn{2}{|c|}{ Macula-Off Eyes, $\mathbf{N}=29$, (\%) } \\
\hline & Baseline & Final & Baseline & Final & Baseline & Final \\
\hline $\log M A R \leq 0.3(\geq 20 / 40)$ & II (23.9) & $20(43.5)$ & II (64.7) & $13(76.5)$ & $0(0)$ & $7(24.1)$ \\
\hline $\begin{array}{l}\log M A R>0.3 \text { to } \leq 1.00 \\
(<20 / 40 \text { and } \geq 20 / 200)\end{array}$ & $10(21.7)$ & $17(37)$ & $3(17.6)$ & $4(23.5)$ & $7(24.1)$ & $13(44.8)$ \\
\hline $\log M A R>1.00(<20 / 200)$ & $25(54.3)$ & $9(19.6)$ & $3(17.6)$ & $0(0)$ & $22(75.9)$ & $9(3 I)$ \\
\hline
\end{tabular}

Abbreviation: logMAR, logarithm of the minimum angle of resolution. 
Table 6 Baseline Characteristics and Operative Factors Associated with Single Surgery Success

\begin{tabular}{|c|c|c|c|c|c|}
\hline \multirow[t]{2}{*}{ Continuous Variables } & \multicolumn{2}{|c|}{ Recurrent Detachment $(\mathrm{N}=16)$} & \multicolumn{2}{|c|}{ Stable Reattachment ( $N=32)$} & \multirow[t]{2}{*}{$P$ Value $^{a}$} \\
\hline & $\mathbf{N}$ & Mean (SD) & $\mathbf{N}$ & Mean (SD) & \\
\hline Age (years) & 15 & 37.44 (19.92) & 32 & $44.56(18.72)$ & 0.418 \\
\hline Follow-up interval (months) & 16 & $51.19(39.64)$ & 32 & $24.50(21.18)$ & 0.001 \\
\hline Baseline LogMAR & 14 & $1.66(1.11)$ & 32 & $1.2563(1.03)$ & 0.361 \\
\hline Categorical Variables & $\mathbf{N}$ & Percentage & $\mathbf{N}$ & Percentage & $P$ value $^{\mathrm{b}}$ \\
\hline \multicolumn{6}{|l|}{ Gender } \\
\hline Male $(\mathrm{N}=40)$ & 14 & 87.5 & 26 & 81.3 & 0.701 \\
\hline Female $(\mathrm{N}=8)$ & 2 & 12.5 & 6 & 18.8 & \\
\hline \multicolumn{6}{|l|}{ Eye } \\
\hline Right $(\mathrm{N}=24)$ & 6 & 37.5 & 18 & 56.3 & 0.359 \\
\hline Left $(N=24)$ & 10 & 62.5 & 14 & 43.8 & \\
\hline \multicolumn{6}{|l|}{ Trauma } \\
\hline No $(N=28)$ & 11 & 68.8 & 17 & 53.1 & 0.363 \\
\hline Yes $(\mathrm{N}=20)$ & 5 & 31.3 & 15 & 46.9 & \\
\hline \multicolumn{6}{|l|}{ Grade C PVR presentation } \\
\hline No $(N=4 I)$ & 13 & 81.3 & 28 & 87.5 & 0.672 \\
\hline Yes $(N=7)$ & 3 & 18.8 & 4 & 12.5 & \\
\hline \multicolumn{6}{|l|}{ Macula Status } \\
\hline Off $(N=31)$ & 14 & 87.5 & 17 & 53.1 & 0.026 \\
\hline On $(N=17)$ & 2 & 12.5 & 15 & 46.9 & \\
\hline \multicolumn{6}{|l|}{ Tamponade agent } \\
\hline Gas $(N=39)$ & 12 & 75 & 27 & 84.4 & 0.457 \\
\hline Silicone oil $(N=9)$ & 4 & 25 & 5 & 15.6 & \\
\hline
\end{tabular}

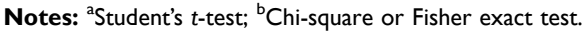

Abbreviations: PVR, proliferative vitreoretinopathy; logMAR, logarithm of the minimum angle of resolution.

previously published series of 41 eyes at our institution reported an $83 \%$ single surgery anatomic success at 3 months in the repair of GRT-associated retinal detachment with a different set of eligibility criteria. ${ }^{1}$ More modern series, including this series, have evaluated primary success with micro-incision vitrectomy surgery (Table 1 ). Pitcher et al found high primary surgical success rates in both the subset of subjects who received an SB (87\%) and those who did not (88\%), although all 10 patients in their series with preoperative PVR-C received $\mathrm{SB} .{ }^{10}$ Additionally, Gonzalez et al and Rodriguez et al reported a combined SSAS of $86 \%$ at their institution in a span of 12 years, although $90 \%$ of their subjects received an encircling band. ${ }^{11,12}$ The current series, which includes traumatic GRTs, PVR, and pediatric patients, demonstrates that SSAS trended higher for those who received SB (87.5\%) compared to those who did not (65\%), although only a small subset of patients received a $\mathrm{SB}$ and this difference was not statistically significant $(P=0.70)$.
These trends are consistent with findings from Goezinne et al, who reported the presence of an encircling SB being significantly associated with reattachment in GRTs, including those with baseline PVR and trauma. ${ }^{8}$ These results suggest that the presence of baseline PVR or risk factors for PVR, such as penetrating eye trauma, may skew the data toward better primary success with the addition of an encircling buckle.

In the present study, SSAS was $75 \%$ at 3 months based on Kaplan-Meier analysis and final anatomic success was $100 \%$ at the last follow-up. Although one may expect improved SSAS in an era of improved vitreoretinal techniques, visualization, and instrumentation as compared to the previous series published from our institution, ${ }^{1}$ it is important to consider that the subjects in this series had an expanded set of eligibility criteria. As seen in other published GRT studies in the modern era of vitrectomy, anatomic success rates vary depending on the surgical technique, whether eyes with PVR or traumatic GRT are 
included, length of follow-up, and age of patients (Table 1). Accordingly, in a large study $(\mathrm{N}=212)$, Scott et al found risk factors for redetachment to include younger age, PVR, and lack of an encircling band placement. ${ }^{17}$ In our series, $42 \%$ of patients presented with a history of ocular trauma, including GRT from penetrating trauma and open globe injury. Our series differs from previous studies in the literature, ${ }^{1,10,21-23}$ including the previous study from our institution, as it did not use penetrating ocular trauma as an exclusion criterion. Furthermore, in the other contemporary published series that did not exclude these cases, GRTs were attributed to trauma in only $16.1 \%$ to $35.3 \%$ of the studied population, lower than the $42 \%$ of GRTs in the present study associated with ocular trauma.,11,13,24,25 Secondly, four subjects ( $8 \%$ ) were under the age of 12 , making it difficult to directly compare our pediatric GRTs to other studies in which the exclusion criteria were those under a certain age. ${ }^{8,10,21,26}$ Although this study did not have sufficient statistical power to detect a statistically significant difference between pediatric $(<12$ years) and adult GRT SSAS rates (50\% vs $68 \%$ ), our results are consistent with pediatric RRDs being generally associated with lower anatomic success rates compared to adult cases. $^{27,28}$ Lastly, only 17 (35.4\%) of our subjects had macula-on detachments which, in accordance with results reported in another case series, ${ }^{1}$ may have significantly lowered the SSAS rate in this report $(P=0.026$, Table 6). Taking these findings into consideration, the relatively poor levels of presenting vision (mean baseline Snellen VA: 20/480) in this study may be considered a reflection of the comparatively high number of macula-involving detachments $(65 \%)$, GRTs $180^{\circ}$ or greater $(27 \%)$, and baseline PVR-C (15\%). Collectively, these factors make our cases of RRD associated with GRT some of the most difficult and complex reported in the literature to date.

With regard to the length of follow-up, recurrent detachments tended to occur several months into followup, averaging 6 months after primary repair with four subjects developing recurrent detachment at greater than 6 months post primary surgical repair. Indeed, the KaplanMeier analysis detailed how the primary surgical success rate decreased over time (Supplemental Figure 1) From 6 months to 2 years after primary repair, the estimated SSAS decreased from $75 \%$ to $65 \%$. These findings coupled with the fact that those with recurrent detachments had significantly longer follow-up than those with stable reattachment (Table 6) suggest that the later recurrent detachments in this series may not be a reflection of the surgical approach, but rather surveillance bias.

Even with a relatively high number of macula-off (65\%), PVR (15\%), and trauma (42\%) cases, the final visual acuity outcomes in this study demonstrated improvement similar to other contemporary series looking at GRT with or without preoperative PVR formation. ${ }^{3,10-12,29}$ Given that $65 \%$ of subjects in this series had a macular detachment at the time of presentation, which significantly worsened both preoperative (logMAR 1.9 macula off vs 0.48 macula on, $P=0.02$ ) and postoperative visual acuity outcomes (logMAR 1.1 macula off vs 0.25 macula on, $P<0.01$ ), the fact that $44 \%$ of patients had a final visual acuity that was $20 / 40$ or better is remarkable. This percentage falls within the upper end of published rates in the modern literature, which reports $16 \%$ to $64 \%$ achieving $20 / 40$ or better at last follow-up. 1,3,10-13,23,25

While there have been large, multicenter, randomized controlled clinical studies ${ }^{14}$ on the treatment of primary RD, the surgical complexity inherent to managing GRTs and the rarity of the condition have not allowed for such trials to be conducted on different approaches to its repair. Instead, a growing number of clinical series, both retrospective and prospective, have demonstrated mixed outcomes in the management of GRTs (Table 1). ${ }^{1,3,8,10-12}$ One area of debate is the choice of tamponade agent in the repair of GRTs. While a small randomized trial of 47 GRTs found no difference in 5-year complications, ${ }^{29}$ anatomic reattachment, and visual outcomes between tamponade with silicone oil or $\mathrm{C}_{3} \mathrm{~F}_{8}$ gas, silicone oil is still the tamponade of choice at most centers worldwide (Table 1). $3,11-13,22-24,29$ Similar to previous studies, we found comparable anatomic outcomes with the use of gas (SSAS $=69 \%$ ) and oil tamponade (SSAS $=56 \%, P=0.457)$. $^{1,3,10-13,22-24,29,30}$ Interestingly, only $9(19 \%)$ eyes in this current series had oil tamponade at primary repair, of whom 2 were pediatric patients who could not position. This percentage is lower than the $48 \%$ to $100 \%$ use of silicone oil described in other recent studies. $^{10-13,22-24,29}$ Silicone oil not only mandates two surgeries but also increases the risk of complications, such as elevated intraocular pressure, corneal toxicity, PVR, and unexplained vision loss. ${ }^{23,31-34}$ Therefore, our findings potentially minimize the tamponade period and occurrence of adverse events in GRT repair. However, the risks of silicone oil need to be balanced with possible benefits, as many modern studies that used a predominance of silicone oil had SSAS rates greater than $80 \% .{ }^{11,13,20,23}$ Lastly, while silicone oil and gas are the common tamponades for GRT 
cases, ${ }^{6}$ Randolph et al looked at an alternative tamponade approach with medium-term tamponade using perfluorocarbons (MT-PFO) and reported comparable anatomic and visual outcomes to other modern studies that employed small-gauge instrumentation (Table 1). ${ }^{21}$

The current series also raises the question of whether the location of the break or lens status should guide surgical decision-making. A predominance $(60 \%)$ of subjects presented with inferior GRTs. While inferior retinal breaks may present a greater challenge to surgical repair in primary $\mathrm{RRD},{ }^{35}$ an interior break location may actually be less cumbersome in the repair of GRT-associated RRDs due to less chance of retinal slippage. While the difference did not reach statistical significance, there was a trend towards better outcomes in patients with superior compared to inferior GRTs (79\% vs 59\%). This trend could be due to several factors, including our preponderance for use of C3F8 tamponade over silicone oil or surgical approach. Despite the notion that supplemental SB can add support to the inferior base, ${ }^{36}$ we did not find a significant difference in SSAS between the PPV and SB subgroups in those with inferior breaks ( $54 \%$ vs $71 \%, P=0.67)$. Furthermore, vitrectomy still remained the most frequently performed operation in this subset of inferior GRT-associated RRDs. Our results suggest that these complicated cases of RRD should not necessarily be managed differently based on the distribution of retinal breaks. In our series, phakic eyes trended towards having worse anatomical outcomes compared to non-phakic eyes (log-rank p-value=0.1489, Supplemental Figure 1). A subgroup of 7/31 (23\%) phakic patients underwent pars plana lensectomy $(\mathrm{N}=4)$ or $\mathrm{KPE} /$ IOL $(\mathrm{N}=3)$ with initial surgery. The rationale for concurrent lensectomy is increased access to anterior structures of the eye and for vitreous base shaving, especially with the consideration that acceleration of nuclear sclerosis after vitrectomy is common in those with pre-existing cataract. $^{6,11}$ However, primary success was attained in only two of four subjects in the pars plana lensectomy subgroup and one of the three subjects in the KPE/IOL subgroup. This suggests that in phakic patients with any amount of cataract, removing this at the time of GRT repair may not improve surgical outcomes to the extent that it outweighs the risk of additional procedures.

In interpreting these results, it is important to acknowledge that this study has several limitations. Due to its retrospective nature, there were inherent differences in follow-up duration, management protocol, and baseline characteristics among subjects. These characteristics of
GRTs, combined with methodological differences and variability in eligibility criteria among studies, make it difficult to draw comparisons between published series of GRT repair. The high rate of PPV and $\mathrm{C}_{3} \mathrm{~F}_{8}$ usage in this study may reflect a bias of the clinical circumstances and investigators. Lastly, the relative rarity of GRTs caused statistical comparisons between many subgroups to be infeasible or underpowered due to inadequate sample size within the groups.

Despite these limitations, this study has its unique strengths. This series offers an investigation of allencompassing GRTs that does not exclude those cases associated with trauma, baseline PVR, clinical syndrome, or children. These factors, compounded by the fact that GRTs constitute some of the most challenging vitreoretinal cases, suggest that favorable anatomic and functional outcomes can be obtained with contemporary surgical approaches.

\section{Conclusion}

Despite the advents of enhanced intraoperative viewing technologies and small-gauge instrumentation which have bolstered surgical success, the management of GRTassociated RRDs remains challenging. Several previous studies have been reported in the literature; however, the applicability of the conclusions from these investigations is largely limited by the exclusion of penetrating trauma, children, and PVR.

This study reviewed the surgical outcomes of all-inclusive GRTs and investigated the impact of multiple variables on anatomic and functional success. The results demonstrate that contemporary repair of some of the most complicated GRTs, including those associated with trauma, PVR, and children, leads to high rates of anatomic and functional success.

\section{Disclosure}

The authors report no conflicts of interest in this work.

\section{References}

1. Jain N, Kozak JA, Niziol LM, Musch DC, Zacks DN Vitrectomy Alone in the Management of Giant Retinal Tears. Ophthalmic Surg Lasers Imaging Retina. 2014;45(5):421-427. doi:10.3928/2325816020140908-03

2. Shunmugam M, Ang GS, Lois N Giant retinal tears. Surv Ophthalmol. 2014;59(2):192-216.

3. Ang GS, Townend J, Lois N Epidemiology of Giant Retinal Tears in the United Kingdom: the British Giant Retinal Tear Epidemiology Eye Study (BGEES). Invest Ophthalmol Vis Sci. 2010;51(9):4781.

4. Aylward GW, Cooling RJ, Leaver PK Trauma-induced retinal detachment associated with giant retinal tears. Retina. 1993;13(2):136-141.

5. Lee SY, Ong SG, Wong DWK, Ang CL Giant retinal tear management: an Asian experience. Eye (Lond). 2009;23(3):601-605. 
6. Berrocal M, Chenworth M, Acaba L Management of giant retinal tear detachments. J Ophthalmic Vis Res. 2017;12(1):93.

7. Michels RG, Rice TA, Blankenship G Surgical techniques for selected giant retinal tears. Retina. 1983;3(3):139-153.

8. Goezinne F, Heij LA EC, Berendschot TTJM, et al. Low redetachment rate due to encircling scleral buckle in giant retinal tears treated with vitrectomy and silicone oil. Retina. 2008;28(3):485-492.

9. Schneider EW, Geraets RL, Johnson MW Pars plana vitrectomy without adjuvant procedures for repair of primary rhegmatogenous retinal detachment. Retina. 2012 32(2):213-219.

10. Pitcher JD, Khan MA, Storey PP, et al. Contemporary Management of Rhegmatogenous Retinal Detachment Due to Giant Retinal Tears: a Consecutive Case Series. Ophthalmic Surg Lasers Imaging Retina. 2015;46(5):566-570. doi:10.3928/23258160-20150521-08

11. Rodriguez M, Lin J, Townsend JH, et al. Giant retinal tears: clinical features and outcomes of vitreoretinal surgery at a university teaching hospital (2011-2017). Clin Ophthalmol. 2018 12;12:2053-2058. doi:10.2147/OPTH.S180353

12. Gonzalez MA, Flynn HW, Smiddy WE, Albini TA, Berrocal AM, Tenzel P Giant retinal tears after prior pars plana vitrectomy: management strategies and outcomes. Clin Ophthalmol. 2013;7:1687-1691.

13. Kumar V, Kumawat D, Bhari A, Chandra P Twenty-five-gauge pars plana vitrectomy in complex retinal detachments associated with giant retinal tear. Retina. 2018;38(4):670-677.

14. Heimann H, Bartz-Schmidt KU, Bornfeld N, Weiss C, Hilgers R-D, Foerster $\mathrm{MH}$ Scleral Buckling versus Primary Vitrectomy in Rhegmatogenous Retinal Detachment. Ophthalmology. 2007;114 (12):2142-2154.e4.

15. McAnany JJ, Genead MA, Walia S, et al. Visual acuity changes in patients with leber congenital amaurosis and mutations in CEP290. JAMA Ophthalmol. 2013;131(2):178-182.

16. Lean JS, Stern WH, Irvine AR, Azen SP Classification of proliferative vitreoretinopathy used in the silicone study. The Silicone Study Group. Ophthalmology. 1989;96(6):765-771.

17. Scott IU, Murray TG, Flynn HW, Feuer WJ, Schiffman JC, Perfluoron Study Group. Outcomes and complications associated with giant retinal tear management using perfluoro-n-octane. Ophthalmology. 2002;109(10):1828-1833.

18. Chang S Giant Retinal Tears: surgical Techniques and Results Using Perfluorocarbon Liquids. Arch Ophthalmol. 1989;107(5):761.

19. Ambresin A, Wolfensberger TJ, Bovey EH Management of giant retinal tears with vitrectomy, internal tamponade, and peripheral 360 degrees retinal photocoagulation. Retina. 2003;23(5):622-628.

20. Kunikata H, Aizawa N, Sato R, Nishiguchi KM, Abe T, Nakazawa T Successful surgical outcomes after 23-, 25- and 27-gauge vitrectomy without scleral encircling for giant retinal tear. Jpn J Ophthalmol. 2020;64(5):506-515.

21. Randolph JC, Diaz RI, Sigler EJ, Calzada JI, Charles S 25-gauge pars plana vitrectomy with medium-term postoperative perfluoro-n-octane for the repair of giant retinal tears. Graefes Arch Clin Exp Ophthalmol. 2016;254(2):253-257.

Clinical Ophthalmology

\section{Publish your work in this journal}

Clinical Ophthalmology is an international, peer-reviewed journal covering all subspecialties within ophthalmology. Key topics include: Optometry; Visual science; Pharmacology and drug therapy in eye diseases; Basic Sciences; Primary and Secondary eye care; Patient Safety and Quality of Care Improvements. This journal is indexed on PubMed

Submit your manuscript here: https://www.dovepress.com/clinical-ophthalmology-journal
22. Kunikata H, Abe T, Nishida K Successful outcomes of 25- and 23-gauge vitrectomies for giant retinal tear detachments. Ophthalmic Surg Lasers Imaging. 2011;42(6):487-492.

23. Hocaoglu M, Karacorlu M, Ersoz MG, Sayman Muslubas I, Arf S Vitrectomy with silicone oil tamponade for retinal detachment associated with giant retinal tears: favourable outcomes without adjuvant scleral buckling. Acta Ophthalmol. 2019;97(2):e271-e276.

24. Banerjee PJ, Chandra A, Petrou P, Charteris DG Silicone oil versus gas tamponade for giant retinal tear-associated fovea-sparing retinal detachment: a comparison of outcome. Eye (Lond). 2017;31(9): 1302-1307.

25. Ghasemi Falavarjani K, Alemzadeh SA, Modarres M, et al. Outcome of surgery in patients with giant retinal tear: 10 years experience. Eye (Lond). 2017;31(9):1284-1289.

26. Kunikata H, Abe T, Nishida K Successful Outcomes of 25- and 23-Gauge Vitrectomies for Giant Retinal Tear Detachments. Ophthalmic Surg Lasers Imaging. 2011;42(6):487-492.

27. Chang P-Y, Yang C-M, Yang C-H, et al. Clinical characteristics and surgical outcomes of pediatric rhegmatogenous retinal detachment in Taiwan. Am J Ophthalmol. 2005;139(6):1067-1072.

28. Weinberg DV, Lyon AT, Greenwald MJ, Mets MB Rhegmatogenous Retinal Detachments in Children: presenting Features and Surgical Outcomes. Invest Ophthalmol Vis Sci. 2002;43(13):618.

29. Batman C, Cekiç O Vitrectomy with silicone oil or long-acting gas in eyes with giant retinal tears: long-term follow-up of a randomized clinical trial. Retina. 1999;19(3):188-192.

30. Moharram HM, Abdelhalim AS, Hamid MA, Abdelkader MF Comparison Between Silicone Oil and Gas in Tamponading Giant Retinal Breaks. Clin Ophthalmol. 2020;14:127-132.

31. Riedel KG, Gabel VP, Neubauer L, Kampik A, Lund OE Intravitreal silicone oil injection: complications and treatment of 415 consecutive patients. Graefes Arch Clin Exp Ophthalmol. 1990;228(1):19-23.

32. McCuen BW 2nd, de Juan E Jr, Landers MB 3rd, Machemer R. Silicone oil in vitreoretinal surgery. Part 2: results and complications. Retina. 1985;5(4):198-205.

33. Moya R, Chandra A, Banerjee PJ, Tsouris D, Ahmad N, Charteris DG The incidence of unexplained visual loss following removal of silicone oil. Eye (Lond). 2015;29(11):1477-1482.

34. Newsom RS, Johnston R, Sullivan PM, Aylward GB, Holder GE, Gregor ZJ Sudden visual loss after removal of silicone oil. Retina. 2004;24(6):871-877.

35. Gartry DS, Chignell AH, Franks WA, Wong D Pars plana vitrectomy for the treatment of rhegmatogenous retinal detachment uncomplicated by advanced proliferative vitreoretinopathy. Br J Ophthalmol. 1993;77(4):199-203.

36. Sharma A Management of primary rhegmatogenous retinal detachment with inferior breaks. Br J Ophthalmol. 2004;88(11):1372-1375
Central and CAS, and is the official journal of The Society of Clinical Ophthalmology (SCO). The manuscript management system is completely online and includes a very quick and fair peer-review system, which is all easy to use. Visit http://www.dovepress.com/ testimonials.php to read real quotes from published authors. 